\title{
PREVALENCE AND FACTORS ASSOCIATED WITH CATARACT AMONG RURAL COMMUNITY ADULTS IN NEGERI SEMBILAN
}

\author{
Azlina Mokhtar ${ }^{1}$, Maimunah Abdul Muna'aim¹, Tengku Amatullah Madeehah Tengku Mohd ${ }^{2}$ and Hafiz \\ Jaafar $^{2}$
}

${ }^{1}$ Ophthalmology Unit, Department of Surgical-based, Faculty of Medicine and Health Sciences, Universiti Sains Islam Malaysia, 71800, Nilai, Negeri Sembilan, Malaysia.

${ }^{2}$ Public Health Unit, Department of Primary Care, Faculty of Medicine and Health Sciences, Universiti Sains Islam Malaysia, 71800, Nilai, Negeri Sembilan, Malaysia.

Corresponding author: Maimunah Abdul Muna'aim

Email: maimunah@usim.edu.my

\begin{abstract}
'Klinik Pakar Mata Bergerak' (KLiP Mobile), translated to specialised ophthalmology mobile clinic is a programme which provides ophthalmology care in the rural community of Negeri Sembilan. This study was conducted to determine the prevalence of cataract and its associated factors among rural adults in Malaysia through an outreach programme of specialised ophthalmology services by KLiP Mobile. This is a cross-sectional study carried out from January 2016 until March 2018 and was conducted in rural areas of all seven districts in the state of Negeri Sembilanvisited by the KLiP Mobile. Universal sampling was applied to all adults attending the mobile clinic. The participants are those who were referred by the government community clinics and walk in patients. The total number of participants in this study was 1480. The mean (SD) age for the study population was $56(16.9)$, by which majority were Malay $(n=1220,82.4 \%)$ and female $(n=809,54.7 \%)$. Most of them received either primary $(n=604,42.4 \%)$ or secondary education $(n=577,40.5 \%)$. The majority of participants were categorized into low income group, with monthly income of less than RM 3,000 ( $n=$ $1118,92.4 \%)$. The prevalence of cataract in the study population was $28.6 \%$. In the multivariate analysis, factors significantly associated with cataract were being male, having no formal education, race and suffering from hypertension. The prevalence of cataract in the rural areas is considerably high. This study highlights the need of baseline information for future study or as the main reference by the policy makers for policy development related to improving vision and eye-care among the populations in Malaysia.
\end{abstract}

Keywords: cataract, rural, prevalence, adult, mobile

\section{INTRODUCTION}

Cataract is one of the most common causes of treatable blindness. It is an opacification of lens inside the eyes, obstructing light from passing and being focused on the retina at the back of the eye, leading to decreased vision. Cataract was reported as the highest cause of avoidable blindness and low vision in Malaysia ${ }^{1}$. A total of 216,000 Malaysians have become blind due to delay of cataract diagnosis according to 2014 National Eye Survey. Untreated cataract (58.6\%) was the commonest cause of moderate and severe visual impairment ${ }^{2}$.

There are many factors associated with cataract. The major contributing factor for cataract development is old age ${ }^{3}$. Other external risk factors for cataract formation are smoking, medication (e.g.: steroids, anti-hypertensive) or diabetes mellitus 4,5 . Diabetes has a strong relation with formation of cataract due to disruption of lens metabolism. Approximately $4 \%$ of all cataract types were attributed to diabetes ${ }^{6}$. Certain occupations, such as farmers, rubber tappers and labourer are also at risk of cataract due to excessive exposure to sunlight ${ }^{7,8}$. These occupations are also associated with lower socioeconomic status, increasing the risk further in these individuals.

Previous studies have found cataract to be more prevalent among those with lower income and lower education ${ }^{1,9,10}$. The rural areas in peninsular Malaysia consists of individuals with lower income and lower education ${ }^{11}$. Those living in the rural areas have less access to specialised services compared to the cities due to lack of facilities and number of specialists ${ }^{12}$. For this reason, a mobile ophthalmology clinic would assist in providing eye services for this vulnerable population.

'Klinik Pakar Mata Bergerak' (KLiP Mobile), translated to specialised ophthalmology mobile clinic is a programme which provides ophthalmology care in the rural community of Negeri Sembilan. It was initiated in 2013 with collaboration between the medical faculty of Universiti Sains Islam Malaysia, the Negeri Sembilan State government, the Health State Department of Negeri Sembilan and the Islamic Religious Council of Negeri Sembilan. The aim of KLiP Mobile is to offer eye examination and eye screening by ophthalmologists to the community in rural and remote areas. Since not many studies explored on the cataract issue among rural population, we conducted this study to describe 
the prevalence of cataract and its associated factors among the community visited by KLiP Mobile team.

\section{METHODS}

A cross-sectional study was carried out from January 2016 until March 2018 in all seven districts of Negeri Sembilan Malaysia. This study was held under the KLiP Mobile programme. and organised by Klinik Pakar Mata Bergerak (KLiP Mobile). Universal sampling was applied in this study, whereby all adults attending the KLiP Mobile programme through referral by the government community health clinic and walk in were included. These include those with poor vision, poorly controlled diabetes mellitus with age more than 50 .

\section{Data collection}

All patients were registered with their name and identification number at every KLiP Mobile programme. Written consent, information on the sociodemographic and medical history were taken during the registration. The examination consisted of visual acuity testing by 3 meters Snellen chart or simplified E chart for those persons who are illiterate. The eye examination was conducted by the ophthalmology team using slit lamp (Topcon $\left.{ }^{\circledR}\right)$. Any greyish or whitish discoloration of the lens was diagnosed as cataract and for the purpose of this study, cataract was defined as the presence of lenticular opacity.

\section{Exposures and Outcome}

The exposure variables included in this study were the sociodemographic factors (age, race, gender, education, income level, smoking status, alcohol intake) and medical history (diabetes mellitus, hypertension, asthma, hyperlipidaemia, renal failure, steroid usage). Race was categorized into Malay, Chinese or Indian while gender was categorized into male or female. For education level, it was further categorized into no education, primary, secondary and tertiary education. As for income level, it was categorized into low income (< RM 3,000), moderate income (RM 3,000 to RM 5,000) and high income (> RM $5,000)$. For smoking status and alcohol intake, the participants were categorized into yes (for smokers and alcoholics) and no (for non-smoker and non-alcoholics). Lastly, for the medical history, the participants were categorized into yes (having the disease) or no (not having the disease). The outcome variable in this study was the diagnosis of cataract and was categorized into cataract and no cataract.

\section{Data Analysis}

Descriptive analysis was conducted to determine the prevalence and sociodemographic factors of the study population. Results for continuous data were presented as mean and standard deviation. For categorical data, the results were presented as frequency and percentage. Bivariate analysis was done to establish any relationship between the exposure variables (sociodemographic factors and medical history) with the outcome variable (diagnosis of cataract). For bivariate analysis, level of significance was pre-set at 0.05. Chisquare test was conducted to determine the association between all the exposure and the outcome variables. For multivariate analysis, multiple logistic regression was used since the primary outcome in this study was a bivariate categorical variable (cataract and non-cataract). Variables with significant results in the bivariate analysis were included for multiple logistic regression analysis. For multiple logistic regression, significance level was pre-set at 0.05 and variables with $p$-value of $<0.05$ were then included in the final regression model. Results for multiple logistic regression were presented in the form of beta coefficient, odds ratio with $95 \%$ confidence interval and $p$-value. Pairwise deletion method was used to address the missing data. All analysis were conducted using SPSS Software.

The procedures used in the study conformed to the tenets of the Declaration of Helsinki. This study was approved by the Ethics Committee of Universiti Sains Islam Malaysia (USIM). Written informed consent was obtained from the subjects prior to data collection and examination.

\section{RESULTS}

The total number of participants included in this study was 1480 . The mean (SD) age for the study population was 56 (16.9). Majority were Malay ( $=1220,82.4 \%)$ and female $(n=809,54.7 \%)$. Most of them received either primary $(n=604,42.4 \%)$ or secondary education $(n=577,40.5 \%)$. The majority of participants were categorized into low income group, with monthly income of less than RM 3,000 ( $n=1118,92.4 \%)$. There were only 253 (17.2\%) and $24(1.6 \%)$ participants who were smoker and drank alcohol respectively.

For the medical history, the two highest comorbidity recorded were hypertension ( $n=664$, $44.9 \%)$ and diabetes mellitus $(n=480,32.5 \%)$. This was followed by hyperlipidaemia, which was detected in 433 (29.3\%) participants. Other medical history such asthma $(n=120,8.1 \%)$, renal failure $(n=24,1.6 \%)$ and steroid usage $(n=6$, $0.4 \%$ ) were also recorded among the study population. Results from descriptive analysis are summarized in Table 1. From 1480, examinations for cataract detection were conducted for 1475 participants. For the right eye, 1090 (73.9\%) were categorized as normal, $23(1.5 \%)$ as dense cataract and $362(24.6)$ as immature cataract. As for the left eye, majority of the participants were categorized as normal ( $n=1067,72.3 \%$ ) followed by immature cataract $(n=361,24.5 \%)$ and dense cataract $(n=47,3.2 \%)$. Overall, the prevalence of cataract detected in the study population was $28.6 \%$. 


\section{Bivariate Analysis}

Chi-square test was used to measure the association between the sociodemographic factors and medical history with the diagnosis of cataract among the study population. Among those diagnosed with cataract, the highest number of patients recorded was Malay $(n=331$, 78.6\%) followed by Chinese $(n=59,14.0 \%)$, Indian $(n=23,5.5 \%)$ and Others $(n=8,1.9 \%)$.

Table 1. Sociodemographic factors and medical history of the study population

\begin{tabular}{|c|c|c|}
\hline Variables & Frequency & Percentage (\%) \\
\hline \multicolumn{3}{|l|}{ Race $(n=1480)$} \\
\hline Malay & 1220 & 82.4 \\
\hline Chinese & 123 & 8.3 \\
\hline Indian & 61 & 4.1 \\
\hline Other & 76 & 5.1 \\
\hline \multicolumn{3}{|l|}{ Gender $(n=1480)$} \\
\hline Male & 671 & 45.3 \\
\hline Female & 809 & 54.7 \\
\hline \multicolumn{3}{|l|}{ Education $(n=1425)$} \\
\hline No education & 114 & 8 \\
\hline Primary & 604 & 42.4 \\
\hline Secondary & 577 & 40.5 \\
\hline Tertiary & 130 & 9.1 \\
\hline \multicolumn{3}{|l|}{ Incomes $(n=1210)$} \\
\hline Low $(<3000)$ & 1118 & 92.4 \\
\hline Moderate $(3000-5000)$ & 73 & 6 \\
\hline High (>5000) & 19 & 1.6 \\
\hline \multicolumn{3}{|l|}{ Smoking $(n=1474)$} \\
\hline Yes & 253 & 17.2 \\
\hline No & 1221 & 82.8 \\
\hline \multicolumn{3}{|l|}{ Alcohol $(n=1473)$} \\
\hline Yes & 24 & 1.6 \\
\hline No & 1449 & 98.4 \\
\hline \multicolumn{3}{|c|}{ Diabetes Mellitus $(n=1479)$} \\
\hline Yes & 480 & 32.5 \\
\hline No & 999 & 67.5 \\
\hline \multicolumn{3}{|l|}{ Hypertension $(n=1480)$} \\
\hline Yes & 664 & 44.9 \\
\hline No & 816 & 55.1 \\
\hline \multicolumn{3}{|l|}{ Asthma $(n=1480)$} \\
\hline Yes & 120 & 8.1 \\
\hline No & 1360 & 91.9 \\
\hline \multicolumn{3}{|c|}{ Hyperlipidaemia $(n=1479)$} \\
\hline Yes & 433 & 29.3 \\
\hline No & 1047 & 70.7 \\
\hline \multicolumn{3}{|l|}{ Renal failure $(n=1480)$} \\
\hline Yes & 24 & 1.6 \\
\hline No & 1455 & 98.4 \\
\hline \multicolumn{3}{|l|}{ Steroid $(n=1480)$} \\
\hline Yes & 6 & 0.4 \\
\hline No & 1474 & 99.6 \\
\hline
\end{tabular}


The prevalence of cataract was also significantly higher ( $p$-value $<0.05)$ among those who had underlying diabetes mellitus (32.4\%), hypertension $(39.4 \%)$, hyperlipidaemia $(35.6 \%)$, asthma $(40.0 \%)$, renal failure $(54.2 \%)$ and history of steroid usage $(66.7 \%)$ as compared to those who did not. No significant association were recorded between the prevalence of cataract with smoking status and alcohol intake. Nevertheless, significantly higher mean age ( $p$-value $<0.001)$ was recorded among those with cataract $($ mean $=$ 68 years, $S D=7.9)$ compared to those without (mean $=50$ years, $S D=16.8)$. Results for bivariate analysis are summarized in Table 2.

\section{Multivariate Analysis}

Multiple logistic regression analysis using generalized linear model was conducted to determine the factors associated with cataract ( $\mathrm{n}$ $=1471)$. Variables with significant results ( $p$-value $<0.05$ ) in the bivariate analysis were included and were further analysed using multiple logistic regression. Initial multiple logistic regression analysis showed significant results ( $p$-value $<0.05$ ) for all variables except for diabetes mellitus $(p-$ value $=0.061)$, income level $(p$-value $=0.998)$, hyperlipidaemia ( $p$-value $=0.413)$, renal failure $(p$-value $=0.589)$ and steroid usage $(p$-value $=$ $0.653)$. As for education level, significant results were seen for 'no education' ( $p$-value $<0.001)$ and 'primary education' ( $p$-value $<0.001$ ) only. The analysis was then rerun with the nonsignificant variables excluded. Gender, education level, hypertension and race, which were included in the subsequent analysis were noted to have a $p$-value of $<0.001$.

Goodness of fit test for the generalised linear model was conducted based on (i) deviance value over degree of freedom (df) ratio and (ii) Pearson chi-square over degree of freedom ratio. The deviance/df ratio of 1.42 and Pearson chisquare/df ratio of 1.45 were recorded. Since both tests showed a ratio of less than 2 , the final regression model was considered to have a good model fit. The highest adjusted odds ratio was recorded by Chinese $(A O R=9.59,95 \% \mathrm{Cl}$ : 4.07 22.56), followed by Indian ( $\mathrm{OR}=6.86,95 \% \mathrm{Cl}$ : 2.66-17.69) and Malay (AOR $=5.49,95 \% \mathrm{Cl}: 2.49$ 12.11). Being male and those diagnosed with hypertension had 1.5 (95\% Cl: 1.19-1.96) and 2.2 (95\% Cl: 1.76-2.86) times higher risk of developing cataract respectively. The final regression model also showed that those with 'no education' and 'primary education' were also found to be significantly associated with cataract $(\mathrm{AOR}=4.98$, 95\% Cl: 3.09-8.04 and AOR $=2.62,95 \% \mathrm{Cl}: 2.03-$ 3.39 respectively). Results for multivariate analysis are summarized in Table 3

Table 2. Bivariate analysis of factors associated with the diagnosis of cataract

\begin{tabular}{|c|c|c|c|}
\hline \multirow{2}{*}{ Variables } & \multicolumn{2}{|c|}{ Cataract } & \multirow{2}{*}{$p$-value } \\
\hline & No & Yes & \\
\hline \multicolumn{4}{|l|}{ Race $(n=1472)$} \\
\hline Malay & 884 & 331 & $<0.001$ \\
\hline Chinese & 63 & 59 & \\
\hline Indian & 36 & 23 & \\
\hline Other & 68 & 8 & \\
\hline \multicolumn{4}{|l|}{ Gender $(n=1471)$} \\
\hline Male & 455 & 210 & 0.02 \\
\hline Female & 595 & 211 & \\
\hline \multicolumn{4}{|l|}{ Education $(n=1417)$} \\
\hline No education & 61 & 52 & $<0.001$ \\
\hline Primary & 370 & 230 & \\
\hline Secondary & 458 & 117 & \\
\hline Tertiary & 116 & 13 & \\
\hline \multicolumn{4}{|l|}{ Incomes $(n=1202)$} \\
\hline Low (< RM 3000) & 752 & 359 & $<0.001$ \\
\hline Moderate (RM 3000-5000) & 65 & 7 & \\
\hline High (>RM 5000) & 19 & 0 & \\
\hline \multicolumn{4}{|l|}{ Smoking $(n=1466)$} \\
\hline Yes & 178 & 73 & 0.89 \\
\hline No & 867 & 348 & \\
\hline
\end{tabular}


Table 2. Continued

\begin{tabular}{|c|c|c|c|}
\hline \multicolumn{4}{|c|}{ Alcohol $(n=1465)$} \\
\hline Yes & 15 & 8 & 0.51 \\
\hline No & 1030 & 412 & \\
\hline \multicolumn{4}{|c|}{ Diabetes Mellitus $(n=1471)$} \\
\hline Yes & 323 & 155 & 0.02 \\
\hline No & 728 & 265 & \\
\hline \multicolumn{4}{|c|}{ Hypertension $(n=1472)$} \\
\hline Yes & 401 & 261 & $<0.001$ \\
\hline No & 650 & 160 & \\
\hline \multicolumn{4}{|c|}{ Asthma $(n=1472)$} \\
\hline Yes & 72 & 48 & 0.004 \\
\hline No & 979 & 373 & \\
\hline \multicolumn{4}{|c|}{ Hyperlipidaemia ( $n=1472)$} \\
\hline Yes & 277 & 153 & $<0.001$ \\
\hline No & 774 & 268 & \\
\hline \multicolumn{4}{|c|}{ Renal failure $(n=1471)$} \\
\hline Yes & 11 & 13 & 0.01 \\
\hline No & 1040 & 407 & \\
\hline \multicolumn{4}{|c|}{ Steroid $(n=1472)$} \\
\hline Yes & 2 & 4 & 0.04 \\
\hline No & 1049 & 417 & \\
\hline
\end{tabular}

Table 3: Final multiple logistic regression model

\begin{tabular}{|c|c|c|c|c|c|}
\hline \multirow{2}{*}{ Parameter } & \multirow{2}{*}{ B } & \multirow{2}{*}{$p$-value } & \multirow{2}{*}{$\begin{array}{c}\text { Adjusted Odds } \\
\text { Ratio }\end{array}$} & \multicolumn{2}{|c|}{$95 \% \mathrm{Cl}$} \\
\hline & & & & Lower & Upper \\
\hline (Intercept) & -3.794 & 0 & 0.022 & 0.01 & 0.051 \\
\hline $\begin{array}{l}\text { Gender } \\
\text { Male }\end{array}$ & 0.424 & $<0.001$ & 1.528 & 1.19 & 1.961 \\
\hline Female & 1.0 & & & . & . \\
\hline $\begin{array}{l}\text { Hypertension } \\
\text { Yes }\end{array}$ & 0.808 & $<0.001$ & 2.242 & 1.756 & 2.863 \\
\hline No & 1.0 & . & & . & . \\
\hline $\begin{array}{l}\text { Education } \\
\text { No education }\end{array}$ & 1.606 & $<0.001$ & 4.983 & 3.088 & 8.039 \\
\hline Has formal education & 1.0 & . & & . & . \\
\hline $\begin{array}{l}\text { Race } \\
\text { Malay }\end{array}$ & 1.704 & $<0.001$ & 5.498 & 2.496 & 12.111 \\
\hline Chinese & 2.26 & $<0.001$ & 9.587 & 4.074 & 22.564 \\
\hline Indian & 1.925 & $<0.001$ & 6.858 & 2.659 & 17.689 \\
\hline Others & 1.0 & . & & & \\
\hline
\end{tabular}

Dependent Variable: Cataract

Model: (Intercept), Gender, Hypertension, Education, Race.

\section{DISCUSSION}

Overall results and prevalence Based on our findings, the prevalence of cataract recorded was $28.6 \%$. It was slightly lower compared to a study conducted by Reddy et al (2008) which found that the overall prevalence of cataract was $32.9 \%{ }^{13}$. One of the main contributors to the difference was the mean age of the study participants. As age has been established as one of the risk factors for cataract development, a study population with a higher mean age would record higher number of cataract $^{13,14}$. In our study, the mean (SD) age was 
lower, 56 (16.9) years old compared to a study by Reddy et al (2008), 63 (13.2) years old and Salowi et al (2015), 64.5 years old ${ }^{13,14}$. Similarly, lower prevalence of cataract $(20.1 \%)$ was recorded by Reddy et al (2004) when the mean age of the study population was younger $(52.9)^{15}$. It should be noted that even though the prevalence of cataract in our population is lower than the overall prevalence, the prevalence should be given attention. Since the rural population is served by the government community clinic and district hospital, it shows that there is still a need for specialised ophthalmology services in the community. There is a waiting list for patients to see ophthalmologist in the hospital, and KLiP Mobile fills this service gap. Up to date, approxiamtely more than 2000 were seen through KLiP Mobile service.

Our study covered a different range of population and socio-demographics background compared to other studies in Malaysia. A study by Reddy et al (2008) was conducted at a referral centre, which may have contributed to a higher prevalence of cataract $^{13}$. Another study by Reddy et al (2004) however was conducted at the rural area in Selangor. Although their study was conducted at the rural area, the total number of study participants was low (311) compared to our study. It also explained why the prevalence of cataract in their study was slightly lower than our findings ${ }^{15}$.

\section{Factors associated with cataract}

In the multivariate analysis, factors significantly associated with cataract were being male, having no formal education, race and suffering from hypertension. Being female has been shown to be associated with higher levels of cataract due to the reduction in the protective effect of estrogen with age progression ${ }^{16-18}$. In this study, although the total number of female cataract patients were higher than male, the overall percentage of cataract to non-cataract participants were higher in male $(31.6 \%)$. The reason could be that male participants in our study suffer from more diseases such as diabetes mellitus and exposed to more high risk behaviour such as smoking compared to females.

Previous studies have shown that lower education is associated with higher levels of cataract ${ }^{17,19}$. Our study also did not find significant association of cataract with low income despite other studies showing that low income individuals have higher cataract. This is because the participants in this study were homogenous and mostly had low household income, therefore a significant association would not be found. In terms of ethnicity, all three races Malay, Chinese and Indian are significantly associated with cataract compared to other races. However, Chinese participants had the highest odd ratio for suffering from cataract compared to other races. But according to a study by Chua et al (2015) in
Singapore, Malays had higher age-standardized prevalence of cataract followed by Chinese and Indians ${ }^{20}$. Given the low number of Chinese participants in this study, it is not possible to make any generalisation in this context. In Malaysia, only the prevalence of low vision and blindness have been reported and not specifically cataract according to ethnicity ${ }^{21-23}$.

One of the main factors that could lead to cataract formation is hypertension. In this study, significant result was found between hypertension with cataract formation. Hypertension is considered to cause elevation of inflammatory cytokines such as tumour necrosis factor-alpha (TNF- $\alpha$ ), interleukin-6(IL-6) and once the blood pressure is raise the $\mathrm{C}$-reactive protein level will elevated and all of this inflammatory cytokines elevation can cause intense systemic inflammation, and lead to pathological pathway of cataract formation ${ }^{24}$. Lee et al. (1997) reported that hypertension could induce alteration of proteins in lens capsules, which could exacerbate the cataract formation ${ }^{25}$. Anti-hypertensive medications have been suggested to be linked to cataract development as well. Potassium sparing anti-hypertensive disturbed the electrolyte balance across the lens fibre membrane which could lead to the formation of cataract. In addition, Beta-blockers also elevated levels of intracellular cyclic adenosine monophosphate, leading in the modification of lens proteins metabolism resulting in lens opacity ${ }^{26}$.

Our study also found that diabetes had significant association with cataract. Uncontrolled diabetic patients will produce high sorbitol level in the lens that affect cells and lens protein metabolism and causing the lens to swell and opaque ${ }^{27}$. The prevalence of diabetes mellitus in our study was $32.5 \%$, similar to the Negeri Sembilan prevalence of $33.2 \%$, highest among all states in Malaysia ${ }^{28}$. Cataracts are two to five times more frequent in patients with diabetes than patients without diabetes. This explains why the prevalence of cataract in our study is high. People with diabetes are not just more likely to develop cataracts, but they are likely to develop them at a younger age and have them progress faster than people without diabetes ${ }^{29}$. In addition, research has shown that people with type 2 diabetes who lower their $\mathrm{HbA} 1 \mathrm{c}$ level by just $1 \%$ can reduce their risk of cataracts by $19 \%{ }^{30}$.

This programme is an example of an "integratedpeople-centred eye care" in the community where focus was given on the promotion, prevention, treatment and rehabilitation ${ }^{31}$. KLiP Mobile programme had given impact to increase the awareness of eye care among community in Negeri Sembilan. Early detection of cataract among community will benefit the low-income community. The benefits to having sight restored by cataract surgery will improve quality of life, health status and social life $\mathrm{e}^{32}$. These data 
highlight the importance of public health strategies targeting low-income and elderly patients, such as regular screening for visual impairment and timely referral to ophthalmologists.

\section{Strengths and Limitations}

KLiP Mobile is the first initiative to deliver mobile outpatient eye services to the community in Malaysia. To the best of our knowledge, this is also the first and largest population-based study that was conducted with specific focus given to the eye-related problems among rural community in Malaysia. The findings of this study could be used as the baseline information for future study or as the main reference by the policy makers for policy development related to improving vision and eyecare among the populations in Malaysia. Nevertheless, some limitations were noted such as homogeneity of rural community background that could dilute the results and missing of important data that should be collected such as Hba1c levels could give us more information with regards to the disease control among the study population.

\section{CONCLUSION}

Prevalence of cataract in the rural population remains high especially in the populations that have restricted access to specialised health services. Healthcare services must continue to conduct health education and outreach programmes to prevent irreversible damage to the eye. It is hoped that the KLiP Mobile initiative can be continued and included as part of the healthcare delivery system especially for the rural areas. The findings from this study serves as a guide to inform policy makers on the importance of early detection, prevention and treatment of cataract and blindness that should be offered to those with limited healthcare access.

\section{Acknowledgment}

The authors would to extend their gratitude to Universiti Sains Islam Malaysia for funding this research (Grant No PPP/FPSK/051000/11017), the staff from the Negeri Sembilan State Health Department and the staff at all the government community clinics involved with KLiP Mobile. In addition, we would like to thank the State Government of Negeri Sembilan, Jabatan Kerja Raya Negeri Sembilan and Majlis Agama Islam Negeri Sembilan for their contribution towards KLiP Mobile.

\section{Conflict of Interest}

There are no conflict of interest among the authors.

\section{Sources of Funding}

Universiti Sains Islam Malaysia Grant No PPP/FPSK/051000/11017.

\section{REFERENCES}

1. Chang JR, Koo E, Agrón E, et al. Risk factors associated with incident cataracts and cataract surgery in the Age Related Eye Disease Study (AREDS). AREDS Report Number 32 . Ophthalmology. 2011;118(11):2113-2119.

doi:https://doi.org/10.1016/j.ophtha.20 11.03.032

2. Chew FL, Salowi MA, Mustari Z, et al. Estimates of visual impairment and its causes from the National Eye Survey in Malaysia (NESII). PLoS One. 2018;13(6):e0198799.

3. Taylor HR. Epidemiology of age-related cataract. Eye. 1999;13(3):445-448. https://www. nature.com/articles/eye19 99119.

4. Wong TY, Loon SC, Saw SM. The epidemiology of age related eye diseases in Asia. $\mathrm{Br} \mathrm{J}$ Ophthalmol. 2006;90(41):506-511.

doi:http://dx.doi.org/10.1136/bjo.2005. 083733

5. Asbell, P.A., Dualan, I., Mindel, J., Brocks, D., Ahmad, M. and Epstein S. Agerelated cataract. Lancet. 2005;365(9459):599-609.

6. Kiziltoprak H, Tekin K, Inanc M, Goker YS. Cataract in diabetes mellitus. World $J$ Diabetes. $\quad 2019 ; 10(3): 140-153$. doi:10.4239/wjd.v10.i3.140

7. Neale RE, Purdie JL, Hirst LW, Green AC. Sun exposure as a risk factor for nuclear cataract. Epidemiology. 2003;14(6):707712.

doi:10.1097/01.ede.0000086881.84657.9 8

8. Theodoropoulou S, Theodossiadis $\mathrm{P}$, Samoli E, Vergados I, Lagiou P, Tzonou A. The epidemiology of cataract: a study in Greece. Acta Ophthalmol. 2011;89(2):e167-e173. doi:10.1111/j.1755-3768.2009.01831.x

9. Athanasiov PA, Casson RJ, Sullivan T, et al. Cataract in rural Myanmar: prevalence and risk factors from the Meiktila Eye Study. Br J Ophthalmol. 2008;92(9):11691174.

doi:http://dx.doi.org/10.1136/bjo.2008. 139725

10. Tang $Y$, Wang $X$, Wang J, et al. Risk factors of age-related cataract in a Chinese adult population: the Taizhou Eye Study. Clin Experiment Ophthalmol. 
2018;46(4):371-379.

doi:https://doi.org/10.1111/ceo.13040

11. Department of Statistics Malaysia. Data Asas Malaysia 2016. http://www.rurallink.gov.my/wpcontent/uploads/2015/05/1-DATA-ASASMALAYSIA1.pdf. Published 2016. Accessed December 1, 2020.

12. Salowi MA, Goh P, Lee PM. The Malaysian Cataract Surgery Registry: Profile of Patients Presenting for The Malaysian Cataract Surgery Registry: Profile of Patients Presenting for Cataract Surgery. Asia-Pacific J Ophthalmol. 2015;4(4):191196. doi: $10.1097 /$ APO. 0000000000000068

13. Reddy SC, Tajunisah I, Low KP, Karmila $A B$. Prevalence of Eye Diseases and Visual Impairment in Urban Population - A Study from University of Malaya Medical Centre. Malaysian Fam Physician. 2008;3(1):2528.

https: / /www.ncbi.nlm.nih.gov/pmc/arti cles/PMC4267024/pdf/MFP-03-25.pdf.

14. Salowi MA, Goh P, Lee PM, Adnan TH, Ismail M. The Malaysian Cataract Surgery Registry: Profile of Patients Presenting for Cataract Surgery. Asia Pacific J Ophthalmol. $\quad$ 2015;4(4):191-196. doi:10.1097/APO.0000000000000068

15. Reddy SC, Ophth MS, Rampal L, Ph D, Nurulaini O, Sc BM. Prevalence and Causes of Visual Impairment and Blindness in a Rural Population in Sepang District , Selangor. Med J Malaysia. 2004;59(2):212217. http: / /www.emjm.org/2004/v59n2/Visual_Impairment _Blindness.pdf.

16. Zhang J, $\mathrm{Xu}$ L, Wang $\mathrm{Y}$, You $\mathrm{Q}$, Ophthalmology JDW-, 2011 U. Five-year incidence of age-related cataract and cataract surgery in the adult population of greater Beijing: the Beijing Eye Study. Ophthalmology. 2011;118(4):711-718. doi:https://doi.org/10.1016/j.ophtha.20 10.08.021

17. Rim TH, Kim DW, Kim SE, Kim SS. Factors associated with cataract in Korea: A community health survey 2008-2012. Yonsei Med J. 2015;56(6):1663-1670. doi:10.3349/ymj.2015.56.6.1663

18. Lewallen S, Courtright P. Gender and use of cataract surgical services in developing countries. Bull World Health Organ. 2002;80:300-303.

https://www.scielosp.org/article/bwho/ 2002.v80n4/300-303/en/.
19. Seddon J, Fong D, West SK, Valmadrid CT. Epidemiology of Risk Factors for AgeRelated Cataract. Surv Ophthalmol. 1995;39(4):323-334.

doi:https://doi.org/10.1016/S0039-

6257(05)80110-9

20. Chua J, Koh JY, Tan AG, Zhao W, Ophthalmology EL-, undefined 2015. Ancestry, socioeconomic status, and agerelated cataract in Asians: the Singapore epidemiology of eye diseases study. Elsevier. $\quad 2015 ; 122(11): 2169-2178$. doi:doi: 10.1016/j.ophtha.2015.06.052. Epub 2015 Aug 6

21. Zainal M, Ismail SM, Ropilah AR, et al. Prevalence of blindness and low vision in Malaysian population: results from the National Eye Survey 1996. $\mathrm{Br} J$ Ophthalmol. 2002;89(9):951-956. doi:http://dx.doi.org/10.1136/bjo.86.9. 951

22. Lundström M, Goh PP, Henry $Y$, et al. The changing pattern of cataract surgery indications: a 5-year study of 2 cataract surgery databases. Ophthalmology. 2015;122(1):31-38.

doi:https://doi.org/10.1016/j.ophtha.20 14.07.047

23. Salowi MA, Goh PP, Lee MY, Adnan TH, Ismail M. The Malaysian Cataract Surgery Registry: profile of patients presenting for cataract surgery. Asia-Pacific $J$ Ophthalmol. 2015;4(4):191-196. doi:10.1097/APO.0000000000000068

24. Bautista LE, Vera LM, Arenas IA, Gamarra $\mathrm{G}$. Independent association between inflammatory markers (C-reactive protein, interleukin-6, and TNF- $\alpha$ ) and essential hypertension. J Hum Hypertens. 2005;19(2):149-154.

doi:https://doi.org/10.1038/sj.jhh.1001 785

25. Lee SM, Lin SY, Li MJ, Liang RC. Possible Mechanism of Exacerbating Cataract Formation in Cataractous Human Lens Capsules Induced by Systemic Hypertension or Glaucoma. karger.com. 1997;29(2):83-90.

doi:https://doi.org/10.1159/000268001

26. Kanthan G, Wang J, ... ER-B journal of, 2009 U. Use of antihypertensive medications and topical beta-blockers and the long-term incidence of cataract and cataract surgery. $\mathrm{Br} J$ Ophthalmol. 2009;93(9):1210-1214.

doi:10.1136/bjo.2008.153379

27. Janghorbani $M$, Janghorbani $M$, Amini M. 
Cataract in type 2 diabetes mellitus in Isfahan, Iran: Incidence and risk factors. Ophthalmic Epidemiol Downloaded from informahealthcare. 2004;11(5):347-358. doi:10.1080/09286580490888753

28. Ministry of Health Malaysia. National Health and Morbidity Survey 2019. Putrajaya; 2019. http://www.iku.gov.my/nhms-2019.

29. Javadi MA, Zarei-Ghanavati S. Cataracts in diabetic patients: a review article. J ophalmic Vis Res. 2008;3(1):52-65. https: / /www.ncbi.nlm.nih.gov/pmc/arti cles/PMC3589218/.
30. Stratton IM, Adler Al, Neil AW, et al. Papers Association of glycaemia with macrovascular and microvascular complications of type 2 diabetes (UKPDS 35): prospective observational study. BMJ. 2000;321(7258):405-412. doi:10.1136/bmj.321.7258.405

31. World Health Organisation. World Report On Vision.; 2019.

32. Lamoureux EL, Fenwick E, Pesudovs K, Tan D. The impact of cataract surgery on quality of life. Curr Opin Ophthalmol. 2011;22(1):19-27.

doi:10.1097/ICU.0b013e3283414284 